\title{
Orientant les transicions a l'educació superior
}

\author{
Alejandro Montes (Universitat Autònoma de Barcelona-GEPS) \\ Aina Tarabini (Universitat Autònoma de Barcelona-GEPS)
}

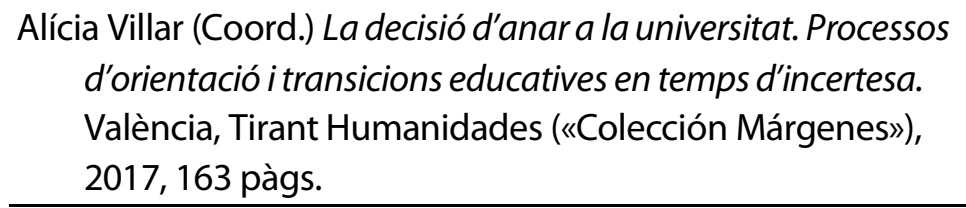

Des de finals del segle $x x$ estem vivint importants processos d'expansió educativa que, als paiisos europeus, han comportat un nombre creixent d'estudiants universitaris i un augment de l'heterogeneïtat tant del seu perfil social com de les vies i itineraris que segueixen per accedir als estudis superiors (Walther, 2006; Bernardi i Requena, 2010; Montes i Tarabini, 2018). En aquest context, el llibre La decisió d'anar a la universitat. Processos d'orientació i transicions educatives en temps d'incertesa aborda un tema d'àmplia rellevància social, tot posant de relleu la importància d'entendre com es construeixen els itineraris vitals dels i les joves en un context d'incertesa, flexibilitat i individualització creixent. Els dos elements claus que vertebren l'anàlisi de forma transversal són, d'una banda, els processos d'orientació que emmarquen les decisions dels joves d'anar cap a la universitat i, d'altra, els discursos socials dominants que legitimen la predominança de les trajectòries universitàries per sobre d'altres opcions educatives enteses socialment com de segona categoria. Tal i com es posa de relleu, els models d'orientació que es porten a terme a bona part dels centres d'educació secundària estan constituïts per una sèrie d'actuacions focalitzades i puntuals, sovint excessivament genèriques i descriptives, poc personalitzades i esbiaixades cap a les vies amb més reconeixement social (el batxillerat). En aquest sentit, l'orientació i l'acció tutorial s'haurien de concebre com accions integrades d'acompanyament del procés educatiu dels joves, amb l'objectiu d'afavorir al màxim el seu desenvolupament acadèmic, personal, professional i emocional (Álvarez i Bisquerra, 2006). Alhora, remarca la importància de donar veu als i les joves en els processos d'orientació i elecció escolar. En aquest sentit, I'anàlisi dels itineraris, les decisions i les biografies educatives dels joves s'ha d'afrontar des d'una perspectiva inclusiva, que vagi més enllà de la mera interpretació objectiva del fet i que aprofundeixi al voltant de com els i les joves construeixen e interpreten la seva subjectivitat i els contextos de pressa de decisió en els que s'emmarquen (Smyth i Hattam, 2001).

El llibre s'estructura a partir d'una presentació inicial, a càrrec de la coordinadora Alícia Villar on es presenta l'objecte d'estudi i els diferents eixos temàtics, seguida de sis capítols analítics i un capítol de conclusió on, de manera global, els diferents autors van desgranant com es construeix la decisió d'anar cap a la universitat. A la presentació es posa de relleu l'objectiu del text i es clarifica l'aproximació metodològica i el treball de camp desenvolupat en el marc del projecte. A 
partir d'un treball de camp basat en 50 entrevistes a joves que estaven cursant el Batxillerat a la Comunitat Valenciana en el curs acadèmic 2014/15, s'ha desenvolupat una anàlisi en profunditat al voltant de com els i les joves construeixen les decisions educatives en les transicions formatives entre l'educació secundària post obligatòria i l'educació superior. Aquest treball de camp es correspon amb una metodologia qualitativa longitudinal, desenvolupant les entrevistes en tres moments seqüencialment correlatius. Alhora, la mostra ha estat estratificada per centres, incloent un centre de tipus públic i un centre de tipus privat-concertat.

El capítol primer, titulat «La decisió d'anar a la universitat. Raons d'una decisió decidida» i escrit per Alícia Villar, ens serveix per contextualitzar el marc on es desenvolupen les transicions educatives $i$ on es gesten les decisions. Alhora, l'autora ens explica de manera panoràmica els principals factors exògens (especialment les expectatives, les quals estan mediades per l'origen social) i endògens (especialment el rendiment acadèmic) que influencien a l'hora de construir la decisió d'anar a la universitat com a una 'decisió decidida', posant de relleu la seva confluència i interacció. Tal i com remarca l'autora, la raó per la qual la 'decisió és decidida' és que tot i que el context evidencia que la inversió en educació superior no es tant rentable com en altres moments o països degut a la poca linealitat de les trajectòries actuals, la presència constant de la precarietat (altes taxes de subocupació o d'atur entre titulats universitaris) o la incertesa que caracteritza el futur dels joves, aquesta segueix present de manera inamovible en els imaginaris dels i les joves com a representació social ideal.

El segon capítol «Educació i Orientació difusa en les transicions a la universitat», elaborat per Francesc J. Hernàndez i Dobon, ens presenta la primera dimensió cabdal que articularà l'origen de les diferents decisions educatives: I'orientació. En aquest sentit, se'ns presenta un model teòric que posa sobre la taula les diferents tipologies d'orientació existents per acabar remarcant, en primer Iloc, la importància d'entendre els processos de decisió com conjuncions de tipologies $i$, en segon terme, posar de relleu la importància del professorat en aquests processos orientadors. Per l'autor, cal anar més enllà dels models clàssics d'orientació endògena $i$ professional, per focalitzar en aquells aspectes més difusos i no intencionals de l'orientació que tant els mitjans de comunicació com la societat, i en especial el professorat, transmeten i retransmeten de manera subtil però profunda en el dia a dia.

I és precisament en el capítol tercer, «Profe, que faig, estudie o treballe? La influència del professorat en els itineraris formatius», coescrit per Elena Giménez i Vicent Horcas, on es focalitza en la figura del professorat i la seva importància en la pressa de decisions futures. En aquests sentit, tal i com afirmen els autors «els itineraris es presenten com a combinacions de possibilitats, dispositius institucionals i normatius i el resultat de la pròpia relació costos-beneficis del mateix itinerari». Alhora, aquest capítol posa de relleu tres elements. En primer Iloc, la potencialitat dels sistemes d'orientació i les limitacions que suposen els actuals models purament descriptivo-informatius. Per als autors, el model actual presenta una orientació de caire pragmàtica i instrumental, on les prioritats queden supeditades a les possibilitats, on manca un acompanyament individualitzat i adaptat a cada cas i que, conseqüentment, dóna lloc a una orientació genèrica, descriptiva, poc holística en els seus recursos i enfocada de manera propedèutica ( $a$ 
les proves i requisits necessaris per a l'accés a la universitat o a la formació professional). En segon terme, la necessitat de repensar el model d'orientació en termes d'un acompanyament més global i al llarg de tota la vida educativa. Com es reafirma durant el capítol, cal avançar cap a una visió més basada en el concepte d'itinerari i en el plantejament biogràfic, és a dir, cap a una orientació basada en el principi de presa de decisions dels joves respecte al seu propi itinerari vital. Finalment, es reflexiona al voltant de la influència que exerceix el professorat sobre l'alumnat ja sigui mitjançant el seu coneixement diferencial de les vies existents, la seva manca de recursos orientadors específics, les expectatives esbiaixades en funció del gènere $o$ l'origen social o les seves preferències personals, entre d'altres factors d'influència.

Si el tercer capítol es centrava en el professorat és en el capítol quart «Anar a la universitat, una decisió només individual? El paper de la família», confegit per Sandra Obiol on ens centrem en el paper de la família com agent cabdal per entendre les decisions educatives dels joves. És precisament en aquest nivell on les desigualtats socials d'origen es fan més paleses, plantejant diferències molt clares tant pel que fa als models donats per descomptat com pel que fa a la provisió de benestar, la configuració de preferències o el grau i tipus d'acompanyament dels fills i filles. En aquest sentit, tal i com diu l'autora: «els fills de famílies amb menys recursos econòmics, posicions laborals més febles i menys capital educatiu són els que fan les decisions de manera més individualitzada i autònoma. El problema és que realment aquests alumnes no són mes autònoms... estan més sols». Aquest fet té com a principals implicacions que les famílies i els alumnes millor situats presentin un major coneixement de les institucions, operin amb un grau més alt d'informació al seu abast, presentin una major facilitat per desenvolupar el càlcul dels riscos i, finalment, que tinguin una major capacitat per interpretar aquesta informació; fet que els deixa en una posició privilegiada respecte a aquells que no disposen de la mateixa qualitat i quantitat de recursos.

Els capítols cinquè i sisè, titulats respectivament «Apropant-nos als discursos que legitimen les decisions preses per estudiants de batxillerat: presentació d'un marc analític» $\mathbf{i}$ «Noves racionalitats en les decisions educatives? Lògiques de justificació en les transicions als itineraris formatius superiors», corren a càrrec de Joan Carles Bernad i Ignacio Martínez i es centren principalment en la figura de I'alumne. L'aportació desenvolupada al voltant d'aquests capítols ens fa raonar sobre les relacions entre agència i estructura i com la seva interrelació acaba definint les decisions i la biografia desenvolupada pels i les joves. En aquest sentit, els autors presenten una proposta holística que articula tres nivells d'influència en la constitució de les decisions educatives. El primer nivell, vinculat als factors individuals i a l'impacte de les característiques personals en les eleccions educatives (preferències subjectives). El segon nivell, relacionat amb la família i els vincles socials del subjecte (expectatives educatives i les influències familiars al voltant de conceptes com el d'habitus). L'últim nivell, centrat al voltant de la idea de l'anàlisi costos-beneficis i les estratègies desenvolupades a cavall entre la gestió dels riscos i la prudència estratègica (específicament rellevant en la consideració de criteris d'autoexclusió i relacionat amb això, en la construcció d'itineraris alternatius o plans b).

Finalment, el llibre conclou amb un capítol final titulat «Orientem-nos: seminari sobre transicions educatives i orientació amb professorat de secundària» i que recull les converses desenvolupades entre 
els membres de l'equip i els professionals de l'educació que van participar en el projecte. Aquesta aportació ens permet observar de primera mà l'enfocament que els professionals de l'orientació desenvolupen, així com les preocupacions i conviccions sobre les que es sustenta aquest enfocament, en un pas més per comprendre les subjectivitats subjacents a processos tant complexes com els que aquí s'analitzen.

En definitiva, i a mode de conclusió, l'obra revisada suposa una aportació rellevant a l'hora d'afrontar un objecte d'estudi innovador en el nostre país, com es l'anàlisi de les transicions educatives cap a l'educació superior, i que presenta una realitat complexa i constantment canviant. Ja sigui pel focus que posa en l'alumnat i les seves subjectivitats, pel discurs crític sobre els mecanismes i sistemes d'orientació o pel reconeixement que efectua sobre el paper de família i, especialment, el professorat, aquesta aportació permetrà de ben segur en un futur ampliar els debats $i$ interpretar amb major precisió i riquesa les eleccions educatives dels i les nostres joves.

\section{Referències}

Álvarez, M. i Bisquerra, R. (2006) «Nous reptes de l'orientació en el context educatiu». Temps d'Educació, núm. 31, p. 179-194.

Bernardi, F. i Requena, M. (2010) «Desigualdad y puntos de inflexión educativos: el caso de la educación post-obligatoria en España». Revista de Educación, número extraordinari, p. 93-118.

Montes, A. i Tarabini, A. (2018, en premsa) «Podemos hablar de equidad en el acceso? Trayectorias, vías y motivaciones de acceso a la educación superior. Un estudio de caso de la
Universidad Autónoma de Barcelona». Educaçao \& Sociedade.

Smyth, J., i Hattam, R. (2001) "Voiced" research as a sociology for understanding 'dropping out' of school». British Journal of Sociology of Education, 22(3), p. 401-415.

Walther, A. (2006) «Regimes of youth transitions: Choice, flexibility and security in young people's experiences across different European contexts». Young, 14(2), p. 119-139. 